\title{
Immunohistochemical expression of heparan sulfate correlates with stromal cell proliferation in breast phyllodes tumors
}

\author{
Chuay-Yeng Koo ${ }^{1}$, Boon-Huat Bay ${ }^{1}$, Philip Chi-Wai Lui ${ }^{2}$, Gary Man-Kit Tse ${ }^{2}$, \\ Puay-Hoon Tan ${ }^{1,3}$ and George Wai-Cheong Yip ${ }^{1}$ \\ ${ }^{1}$ Department of Anatomy, Yong Loo Lin School of Medicine, National University of Singapore, Singapore; \\ ${ }^{2}$ Department of Anatomical and Cellular Pathology, Chinese University of Hong Kong, Hong Kong and \\ ${ }^{3}$ Department of Pathology, Singapore General Hospital, Singapore
}

\begin{abstract}
Phyllodes tumors are fibroepithelial neoplasms typified by stromal proliferation. We have previously shown the role of pathologic parameters and the prognostic significance of p53 and CD117 protein expression in these tumors. In this study, we evaluated the expression of heparan sulfate, which has been implicated in many biological processes such as cell adhesion, embryogenesis, and tumorigenesis (including malignant transformation of mammary cells) in 232 breast phyllodes tumors. We used a monoclonal antibody, 10E4, to examine the localization of heparan sulfate in phyllodes tumors by immunohistochemistry. The immunoreactivity of both epithelial and stromal components was examined and analyzed with pathological parameters and other immunohistochemical markers, including p53, MIB1, bcl2, and CD117. Stromal 10E4 expression was significantly associated with tumor grade, stromal p53, and MIB1 expression in proliferating cells, suggesting that heparan sulfate may participate in malignant tumor growth.

Modern Pathology (2006) 19, 1344-1350. doi:10.1038/modpathol.3800657; published online 7 July 2006
\end{abstract}

Keywords: heparan sulfate; phyllodes tumor grade; immunohistochemistry; tissue microarray

Heparan sulfate is an important biomolecule that is essential in maintaining cell-cell and cell-extracellular matrix adhesion, mediating receptor-ligand binding and regulating the activities of growth and motility factors. ${ }^{1-3}$ Its primary structure is characterized by repeats of disaccharide units of a uronic acid and a derivative of glucosamine. The biosynthetic process of heparan sulfate is highly complicated whereby it can undergo modifications such as sulfation, epimerization, and acetylation to generate a great structural diversity of heparan sulfate chains. ${ }^{4,5}$ These chains are covalently attached to core proteins to form heparan sulfate proteoglycans. There is accumulating evidence highlighting the influence of heparan sulfate in modulating many

Correspondence: Dr P-H Tan, FRCPA, Department of Pathology, Singaopre General Hospital, Outram Road, Singapore 169608, Singapore.

E-mail: tan.puay.hoon@singhealth.com.sg

Dr GW-C Yip, MBBS, PhD, Department of Anatomy, Yong Loo Lin School of Medicine, Block MD 10, Singapore 117597, Singapore. E-mail: georgeyip@nus.edu.sg

Received 3 April 2006; revised 5 June 2006; accepted 7 June 2006; published online 7 July 2006 physiological processes and diseases such as cancer. Studies have indicated that this molecule may be altered structurally during malignant transformation of colon cancer cells and indirectly promote growth factor signalling, leading to tumor cell proliferation. ${ }^{6}$ Differential heparan sulfation patterns in breast cancer cells have been demonstrated by various groups. ${ }^{7-10}$ Safaiyan et $a l^{11}$ have shown that there is selective reduction of 6-O sulfation in heparan sulfate from transformed breast epithelial cells. Several reports have also shown that syndecan 1 is an important heparan sulfate proteoglycan in cell signalling and tumor cell progression in breast cancer. ${ }^{11-15}$

Phyllodes tumors of the breast, originally termed cystosarcoma phyllodes, are uncommon fibroepithelial neoplasms, ${ }^{16}$ typified by hypercellular stroma and elongated ducts with irregular leaf-like patterns due to stromal proliferation. ${ }^{17}$ Its numbers are much fewer than breast carcinomas, with a proportion of only $1.5 \%$ compared to breast carcinomas. Phyllodes tumors have a higher frequency in Asian women. ${ }^{18,19}$ Classification into three categories of benign, borderline and malignant is based on a 
spectrum of histological features such as stromal hypercellularity, mitotic rate, and nature of microscopic margins. However, there are still difficulties in accurate categorization of phyllodes tumors and predicting their clinical outcome. ${ }^{18}$

Several biological molecules such as p53, MIB1, and CD34 have been demonstrated to be possible prognostic indicators in phyllodes tumors. ${ }^{16,20-22}$ As heparan sulfate has been shown to be differentially expressed in many forms of cancers including breast cancers, we aimed to investigate its relationship with malignant progression in phyllodes tumors by immunohistochemistry using the 10E4 monoclonal antibody. The epitope of 10E4 has been shown to consist of mixed N-sulfated and $\mathrm{N}$-acetylated heparan sulfate. ${ }^{23}$ Apart from correlating the immunohistochemical results with histological parameters, we also compared its expression with MIB1, p53, bcl2, and CD117 expression. To the best of our knowledge, this is the first study evaluating the role of heparan sulfate in breast phyllodes tumors.

\section{Materials and methods}

\section{Clinical Materials}

Previously constructed tissue microarray blocks of archival breast phyllodes tumor specimens from the Department of Pathology, Singapore General Hospital were used for this study. ${ }^{19}$ Clinicopathological information collected included patient age, tumor size, macroscopic features of hemorrhage, myxoid or necrotic changes, cystic degeneration; microscopic alterations of mitotic activity, stromal hypercellularity and overgrowth, nature of borders and stromal cytologic atypia. Immunohistochemical data on the proliferating index (MIB1), p53, bcl2, and CD117 were also available. ${ }^{24}$

\section{Immunohistochemistry}

10E4 monoclonal antibody was purchased from Seikagaku Corporation (Tokyo, Japan). Briefly, paraffin-embedded tissue microarray sections ( $4 \mu \mathrm{m}$ thickness) were deparaffinized, rehydrated, and endogenous peroxidase activity was quenched with $3 \% \mathrm{H}_{2} \mathrm{O}_{2}$ for $15 \mathrm{~min}$. Antigen retrieval was performed by incubation with $0.1 \mathrm{mg} / \mathrm{ml}$ testicular hyaluronidase for $2 \mathrm{~h}$ at room temperature prior to overnight incubation at $4^{\circ} \mathrm{C}$ with $10 \mathrm{E} 4$ antibody (1:150 dilution). After washing with Tris-buffered saline, biotinylated secondary antibody was added and incubated for $1 \mathrm{~h}$ at room temperature. Visualization was achieved by the avidin-biotin-complex technique (ABC kit, Vector Laboratories) using diaminobenzidine as the substrate, followed by counterstaining with hematoxylin.

Sections were examined using an Olympus BX 51 microscope (Olympus, Tokyo, Japan) and photographed with an Olympus DP50 CCD camera. Two images were selected randomly of each specimen and analyzed using Image J v1.33 software $(\mathrm{NIH}$, USA) with the color deconvolution plugin to measure staining intensities of the areas of interest. ${ }^{25}$ The mean heparan sulfate staining intensities of the stromal and epithelial compartments of phyllodes tumors were measured separately in arbitrary units and later converted into an immunoreactivity score where $0=$ no staining, $1=$ weak staining, $2=$ moderate staining, and $3=$ strong staining. For MIB1, p53, bcl2, and CD117, any staining of nuclei (MIB1, p53) or cytoplasm (bcl2, CD117) were considered positive reactivity. Table 1 shows details of these antibodies.

\section{Statistical Analysis}

Statistical analysis was carried out using GraphPad Prism 4 for Windows (GraphPad Software, San Diego, CA, USA). Immunoreactivity scores for heparan sulfate staining were correlated with clinicopathological parameters and immunohistochemical staining results of MIB1, p53, bcl2, and CD117, using Chisquare test or Fisher's exact test. The Mann-Whitney $U$-test was used to compare means between variables. Differences were considered to be statistically significant when $P$-values were $<0.05$.

\section{Results}

We have documented the clinicopathological data of the largest phyllodes tumor series in literature to

Table 1 Details of antibodies, dilutions and antigen retrieval methods

\begin{tabular}{|c|c|c|c|c|}
\hline Antibody & Catalogue No. & Dilution & Pretreatment method & Clone \\
\hline MIB1 & Dako M7240 & $1: 300$ & $\begin{array}{l}\text { Microwave (using National MW oven NN-S650 WF) in Milestone T/T Mega, } \\
\text { at } 98^{\circ} \mathrm{C} \text { for } 12 \text { min in Ventana CC1 Solution, Code No. } 950-124\end{array}$ & SP6 \\
\hline p53 & Dako M7001 & $1: 70$ & $\begin{array}{l}\text { Microwave (using National MW oven NN-S650 WF) in Milestone T/T Mega, } \\
\text { at } 98^{\circ} \mathrm{C} \text { for } 12 \text { min in Ventana CC1 Solution, Code No. } 950-124\end{array}$ & D07 \\
\hline Bcl2 & Dako M0887 & $1: 10$ & $\begin{array}{l}\text { Pressure cook in microwave oven, Milestone T/T Mega, at } 98^{\circ} \mathrm{C} \text { for } 10 \mathrm{~min} \text { in } \\
\text { DakoCytomation Target Retrieval Solution, High pH, Code No. S3307 }\end{array}$ & 124 \\
\hline CD117 & Dako A4502 & $1: 200$ & $\begin{array}{l}\text { Microwave (using National MW oven NN-S650 WF) in Milestone T/T Mega, } \\
\text { at } 98^{\circ} \mathrm{C} \text { for } 12 \text { min in Ventana CC1 Solution, Code No. } 950-124\end{array}$ & $\mathrm{Ra}$ \\
\hline
\end{tabular}

MW, microwave. 
date of 335 women with breast phyllodes tumors. ${ }^{19}$ Owing to loss of some sections of individual cores during cutting of the tissue microarray blocks, immunohistochemical analysis using 10E4 was performed on 232 microarrays out of the original 335 cases. Among these, 163 were diagnosed as benign, 36 as borderline, and 33 as malignant.

As shown in Figure 1, the 10E4 epitope was present in higher amounts in the basement membranes and perithelial regions of phyllodes tumors, with $11.2 \%$ of cases demonstrating accentuated decoration of the basement membrane and stroma immediately around epithelial elements of these tumors. Stromal and epithelial expression of 10E4 was detected in 35.3 and $46.6 \%$ of phyllodes tumors, the latter in the cytoplasm of epithelial cells. The findings are summarized in Table 2. There was no significant association between the intensity of $10 \mathrm{E} 4$ epithelial staining and tumor grade $(P=0.400)$. However, there was a significant difference in 10E4 expression in the stromal component of phyllodes tumors among the tumor grades $(P=0.0188$, Figures 1 and 2 ; negative control, Figure 3).

The expression of $10 \mathrm{E} 4$ epitope in the stromal compartment of phyllodes tumors was compared with other histological features, as depicted in

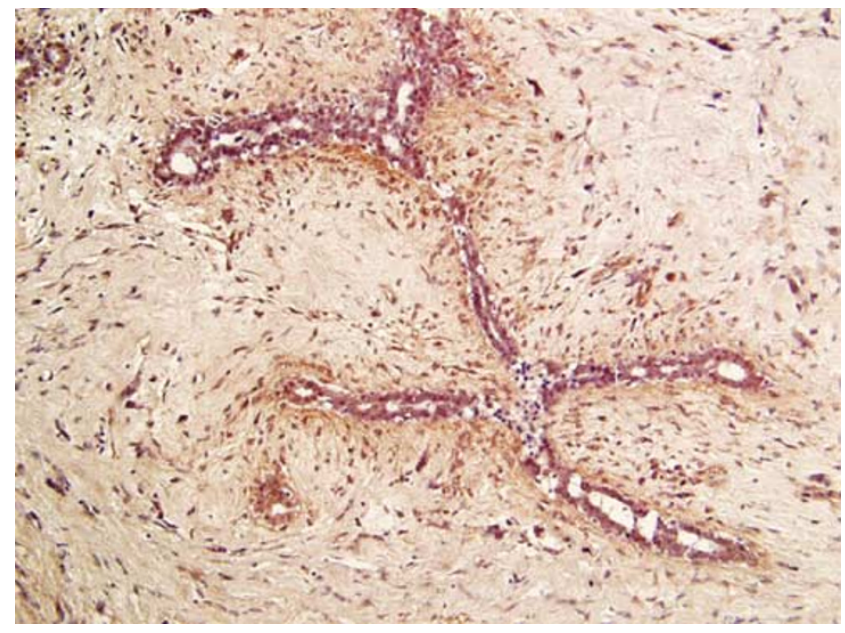

Figure 1 Perithelial accentuation of heparan sulfate 10E4 immunohistochemical staining in a benign phyllodes tumor.
Table 3. We also compared 10E4 expression with immunohistochemical detection of MIB1, p53, bcl2 and CD117. Interestingly, statistically significant correlations were found between 10E4 stromal positivity with p53 and CD117 stromal staining. We had previously reported the latter two parameters

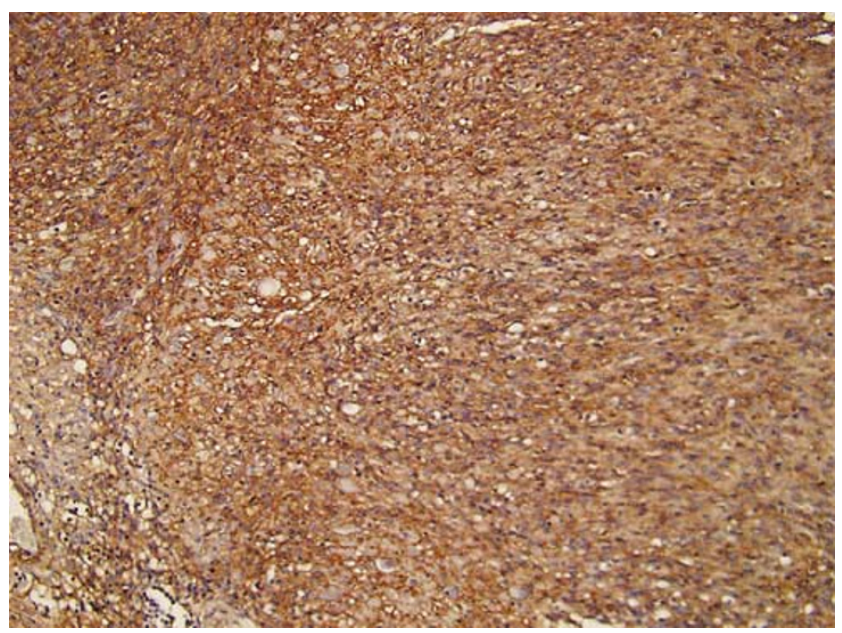

Figure 2 Diffuse intense stromal staining for heparan sulfate 10E4 in a malignant phyllodes tumor with stromal overgrowth.

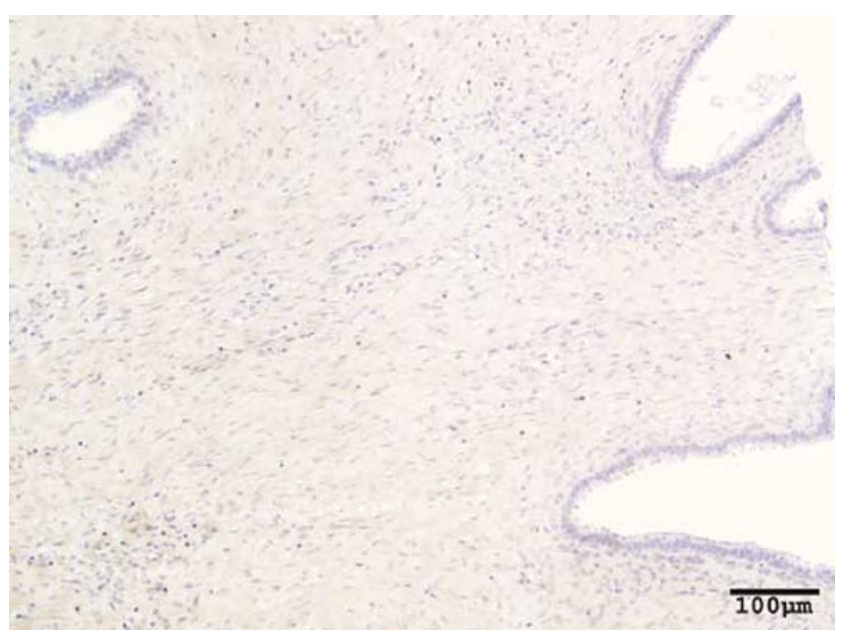

Figure 3 Negative control section accomplished by omitting the primary antibody.

Table 2 Immunohistochemical expression of heparan sulfate 10E4 in benign, borderline and malignant phyllodes tumors

\begin{tabular}{|c|c|c|c|c|c|c|c|c|}
\hline & \multicolumn{4}{|c|}{$10 E 4$ expression in stromal compartment } & \multicolumn{4}{|c|}{$10 E 4$ expression in epithelial compartment } \\
\hline & Total number & $I R S \leq 0$ & $\operatorname{IRS}>0$ & $\mathrm{P}$-value & Total number & $I R S \leq 0$ & IRS $>0$ & $\mathrm{P}$-value \\
\hline Benign & 163 & 114 & 49 & & 159 & 89 & 70 & \\
\hline Borderline & 36 & 21 & 15 & & 34 & 17 & 17 & \\
\hline Malignant & 33 & 15 & 18 & $0.0188^{\mathrm{a}}$ & 28 & 12 & 16 & 0.4001 \\
\hline Total & 232 & 150 & 82 & & 221 & 118 & 103 & \\
\hline
\end{tabular}

IRS: immunoreactivity score.

${ }^{\mathrm{a}}$ Statistically significant result. 
Table 3 Clinicopathologic features of phyllodes tumors correlated with $10 \mathrm{E} 4$ stromal immunostaining

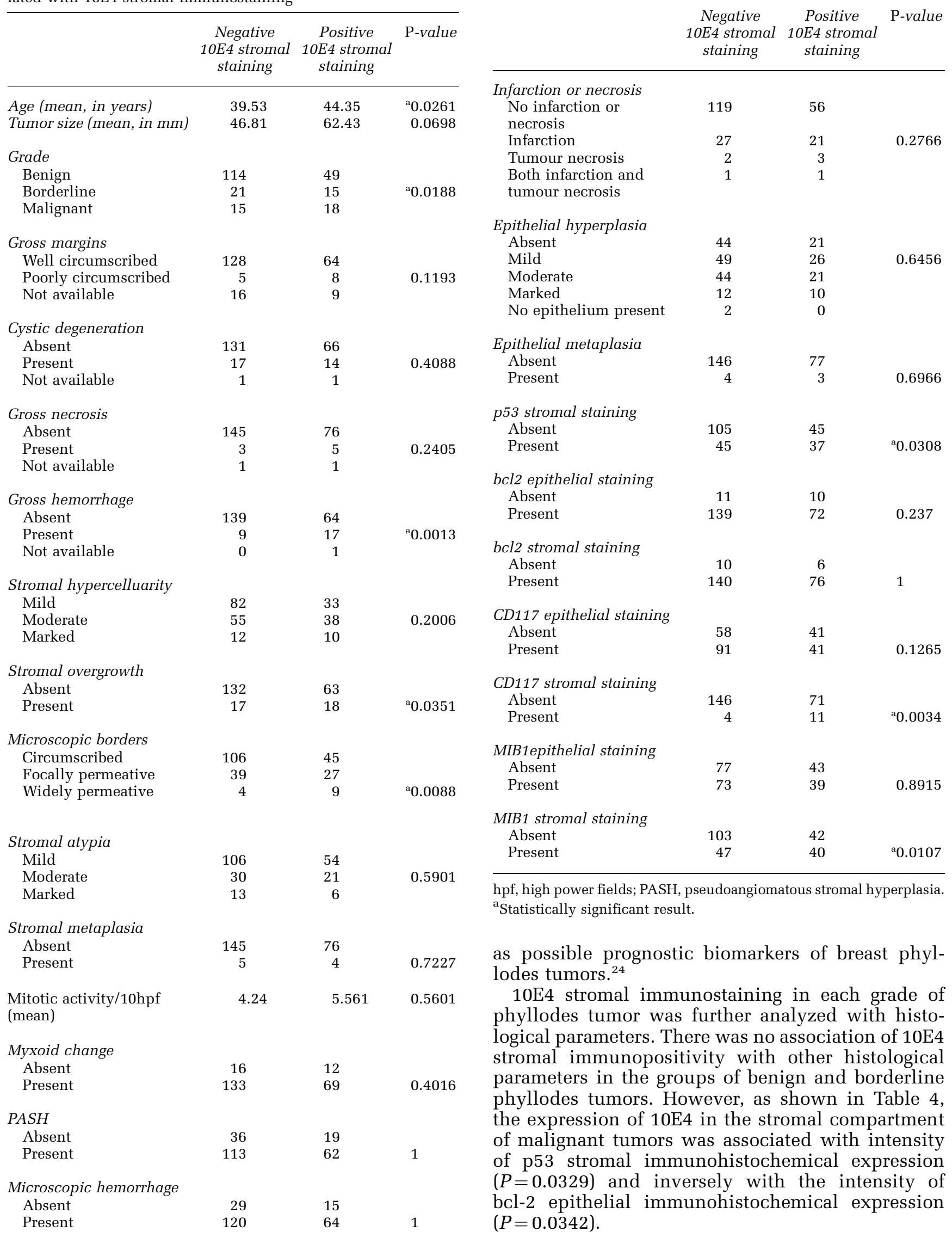

Table 3 Continued

(n)


Table 4 Immunohistochemical expression of p53 and bcl2 compared against stromal 10E4 expression in malignant phyllodes tumors

10E4 expression in stromal component

\begin{tabular}{lcrcr} 
& Total number & IRS $\leq 0$ & IRS $>0$ & P-value \\
\hline p53 stromal & expression & & & \\
IRS $\leq 1$ & 19 & 12 & 7 & \\
IRS $>1$ & 14 & 3 & 11 & $0.0329^{\mathrm{a}}$ \\
Total & 33 & 15 & 18 & \\
& & & & \\
bcl2 epithelial expression & & & \\
IRS $\leq 0$ & 11 & 2 & 9 & \\
IRS $>0$ & 22 & 13 & 9 & $0.0342^{\mathrm{a}}$ \\
Total & 33 & 15 & 18 & \\
\hline
\end{tabular}

IRS, immunoreactivity score.

IRS for p53 stromal and bcl2 epithelial expression is based on the intensity of immunohistochemical staining of the stromal cell nucle and the epithelial cell cytoplasm respectively, quantified from 0 to 3 . ${ }^{\mathrm{a}}$ Statistically significant result.

\section{Discussion}

In the present study, we have shown that heparan sulfate recognized by the $10 \mathrm{E} 4$ antibody is found in the basement membranes and perithelial regions of phyllodes tumors, with expression being stronger in the perithelial stromal region. 10E4 antibody is a widely-used antibody for the detection and localization of heparan sulfate in tissues. ${ }^{26-28}$ Leteux et $a l^{29}$ reported that $10 \mathrm{E} 4$ recognized a heparan sulfate tetrasaccharide in which an N-unsubstituted GlcN residue was required for the binding to $10 \mathrm{E} 4$. More recently, it was shown that a mixed $\mathrm{N}$-sulfated/Nacetylated epitope was necessary for 10E4 binding. ${ }^{23}$ Unfortunately, to date, the exact structure of the heparan sulfate epitope recognized by the 10E4 antibody is still not fully characterized.

The well-known MIB1 antibody recognizes Ki-67, a nuclear nonhistone protein that is strictly linked to cell proliferation. ${ }^{30,31}$ The expression of $\mathrm{Ki}-67$ in active phases of the cell cycle $\left(G_{1}, S, G_{2}\right.$ and $\left.M\right)$ and its absence in the $G_{0}$ resting phase makes it a common and useful marker for assessing the degree of cell proliferation. ${ }^{32,33}$ Previously, studies have shown a high degree of correlation of stromal Ki-67 expression with phyllodes tumor grade. ${ }^{34,35}$ In our present study, a significant correlation between stromal 10E4 expression and stromal MIB1 expression was observed. Thus, we postulate that heparan sulfate chains detected by the 10E4 antibody may have a role in controlling the proliferation of stromal cells in phyllodes tumors. Heparan sulfate is an accessory molecule essential for stabilizing the binding of growth factors to their receptors. For example, it regulates the activation of fibroblast growth factor receptors by fibroblast growth factors to elicit a series of downstream events, such as cell proliferation. ${ }^{36-38}$ Several reports have suggested that alterations in the expression or biosynthesis of heparan sulfate are responsible for the differential affinities of fibroblast growth factor 1 and fibroblast growth factor 2 with their receptors, thus promoting breast cancer cell progression, metastasis and angiogenesis. ${ }^{39-41}$ Hence, it is possible that heparan sulfate may manipulate the proliferative acitivity of the stroma in phyllodes tumors through the fibroblast growth factor/fibroblast growth factor receptor signalling pathways.

p53 is a tumor suppressor that has a main role as a gatekeeper in preventing cells with damaged DNA from proceeding further in the cell cycle. Defective p53 expression can result in neoplastic transformation in many different cell types, including breast epithelial cells. ${ }^{42-44}$ Thus far, it has been reported that p53 stromal expression increases from benign to malignant grades in phyllodes tumors and its expression has been related to various histological parameters, such as mitotic count and stromal overgrowth. ${ }^{20,21,45}$ Our findings show a statistically significant relationship between 10E4 stromal staining and p53 expression in the stroma, suggesting the possibility that 10E4-specific heparan sulfate species may play an indirect role in phyllodes tumor pathogenesis and increased p53 expression. Furthermore, more intense p53 stromal staining is associated with $10 \mathrm{E} 4$ stromal positivity in malignant tumors. Shpitz et al has reported that the expression of p53 tends to be higher in phyllodes tumors of higher malignant potential. ${ }^{46}$ Thus, it is possible that heparan sulfate may cooperate with p53 in regulating cell cycle progression in phyllodes stromal cells. Also, the epithelial expression of bcl2, a well-known antiapoptotic protein, is decreased in malignant phyllodes tumors with little or no 10E4 staining. Several studies have reported an inverse relationship between p53 and bcl2. Krajewski et $a l^{47,48}$ concluded that the regulation of bcl2 is associated with alterations in p53. The correlation of 10E4 epitope with p53 and bcl2 suggests that these molecules may be involved in malignant transformation of cells in phyllodes tumors.

We also found a close association of 10E4 stromal staining with CD117 stromal staining. CD117 is a membrane bound tyrosine kinase receptor that is well known for controlling many cell signalling processes through the Ras/MAP kinase pathway and JAK/STA signalling. It is a well-known marker for gastrointestinal stromal tumors. ${ }^{49}$ Some phyllodes tumors may be thought to bear similarity to gastrointestinal stromal tumors in that the latter also contain a spindle cell component of neoplastic CD34 positive cells. ${ }^{50}$ In concert with recent reports, we had previously suggested CD117 as a possible prognostic biomarker for phyllodes tumors and that it may be involved in the early development of these tumors. ${ }^{24,50,51}$ In this study, we hypothesize that heparan sulfate may be involved in ligand activation of CD117 and lead to cellular proliferation.

In summary, we have demonstrated that higher stromal expression of heparan sulfate is present in 
higher grades of phyllodes tumors. The correlation of heparan sulfate immunopositivity with p53, bcl2 and CD117 provides strong evidence that they may work together to control cell cycle progression in these tumors. In the majority of the associations discussed above, expression of various immunohistochemical markers was confined within the stromal region, supporting the notion that neoplastic activity occurs mostly in the stromal rather than epithelial component in phyllodes tumors. ${ }^{20,52}$ Categorization of such tumors into their respective grades can be potentially aided by using a combination of $10 \mathrm{E} 4$ antibody together with antibodies against other well-known biomarkers MIB1 and p53. The relevance of heparan sulfate expression in breast phyllodes tumors in routine surgical pathology practice may lie in not only more accurate assignment of tumor grade, but in the prediction of biologic behavior. Confirmation of heparan sulfate expression in phyllodes tumor stroma can lead to further understanding of the pathogenesis of this tumor and impact on possible therapeutic modulations.

\section{Acknowledgements}

The project was supported by grants from the Singapore Cancer Syndicate MS0004 and the National Medical Research Council NMRC/0772/2003, Singapore. CYK was the recipient of a graduate research scholarship from the National University of Singapore.

\section{References}

1 Kolset SO, Prydz K, Pejler G. Intracellular proteoglycans. Biochem J 2004;379:217-227.

2 Kramer KL, Yost HJ. Heparan sulfate core proteins in cell-cell signaling. Annu Rev Genet 2003;37:461-484.

3 Sanderson RD, Bernfield M. Molecular polymorphism of a cell surface proteoglycan: distinct structures on simple and stratified epithelia. Proc Natl Acad Sci USA 1988;85:9562-9566.

4 Esko JD, Selleck SB. Order out of chaos: assembly of ligand binding sites in heparan sulfate. Annu Rev Biochem 2002;71:435-471.

5 Sugahara K, Kitagawa H. Heparan and heparan sulfate biosynthesis. IUBMB Life 2002;54:163-175.

6 Jayson GC, Lyon M, Paraskeva C, et al. Heparan sulfate undergoes specific structural changes during the progression from human colon adenoma to carcinoma in vitro. J Biol Chem 1998;273:51-57.

7 Alini M, Losa GA. Partial characterization of proteoglycans isolated from neoplastic and nonneoplastic human breast tissues. Cancer Res 1991;51:1443-1447.

8 Gowda DC, Bhavanandan VP, Davidson EA. Structures of O-linked oligosaccharides present in the proteoglycans secreted by human mammary epithelial cells. J Biol Chem 1986;261:4935-4939.

9 Koda JE, Bernfield M. Heparan sulfate proteoglycans from mouse mammary epithelial cells. Basal extra- cellular proteoglycan binds specifically to native type I collagen fibrils. J Biol Chem 1984;259:11763-11770.

10 Rapraeger A, Bernfield M. Cell surface proteoglycan of mammary epithelial cells. Protease releases a heparan sulfate-rich ectodomain from a putative membraneanchored domain. J Biol Chem 1985;260:4103-4109.

11 Safaiyan F, Lindahl U, Salmivirta M. Selective reduction of 6-O-sulfation in heparan sulfate from transformed mammary epithelial cells. Eur J Biochem 1998;252:576-582.

12 Beauvais DM, Rapraeger AC. Syndecan-1-mediated cell spreading requires signaling by alphavbeta3 integrins in human breast carcinoma cells. Exp Cell Res 2003;286:219-232.

13 Bernfield M, Sanderson RD. Syndecan, a developmentally regulated cell surface proteoglycan that binds extracellular matrix and growth factors. Philos Trans R Soc Lond B Biol Sci 1990;327:171-186.

14 Mali M, Andtfolk H, Miettinen HM, et al. Suppression of tumor cell growth by syndecan-1 ectodomain. J Biol Chem 1994;269:27795-27798.

15 Stanley MJ, Stanley MW, Sanderson RD, et al. Syndecan-1 expression is induced in the stroma of infiltrating breast carcinoma. Am J Clin Pathol 1999;112:377-383.

16 Ridgway PF, Jacklin RK, Ziprin P, et al. Perioperative diagnosis of cystosarcoma phyllodes of the breast may be enhanced by MIB-1 index. J Surg Res 2004;122: 83-88.

17 Fechner RE, Mills SE. Breast pathology: Benign proliferations, atypias and in situ carcinomas 1990, American Society of Clinical Pathologists: Chicago.

18 Moffat CJ, Pinder SE, Dixon AR, et al. Phyllodes tumors of the breast: a clinicopathological review of thirty-two cases. Histopathology 1995;27:205-218.

19 Tan PH, Jayabaskar T, Chuah KL, et al. Phyllodes tumors of the breast: the role of pathologic parameters. Am J Clin Pathol 2005;123:529-540.

20 Feakins RM, Wells CA, Young KA, et al. Plateletderived growth factor expression in phyllodes tumors and fibroadenomas of the breast. Hum Pathol 2000;31: 1214-1222.

21 Kuenen-Boumeester V, Henzen-Logmans SC, Timmermans MM, et al. Altered expression of p53 and its regulated proteins in phyllodes tumors of the breast. J Pathol 1999;189:169-175.

22 Moore T, Lee AH. Expression of CD34 and bcl-2 in phyllodes tumors, fibroadenomas and spindle cell lesions of the breast. Histopathology 2001;38:62-67.

23 van den BJ, Salmivirta K, Henttinen T, et al. Novel heparan sulfate structures revealed by monoclonal antibodies. J Biol Chem 2005;280:20516-20523.

24 Tan PH, Jayabaskar T, Yip G, et al. p53 and c-kit (CD117) protein expression as prognostic indicators in breast phyllodes tumors: a tissue microarray study. Mod Pathol 2005;18:1527-1534.

25 Ruifrok AC, Johnston DA. Quantification of histochemical staining by color deconvolution. Anal Quant Cytol Histol 2001;23:291-299.

26 Fuxe K, Chadi G, Tinner B, et al. On the regional distribution of heparan sulfate proteoglycan immunoreactivity in the rat brain. Brain Res 1994;636: 131-138.

27 Oshiro M, Ono K, Suzuki Y, et al. Immunohistochemical localization of heparan sulfate proteoglycan in human gastrointestinal tract. Histochem Cell Biol 2001;115:373-380. 
28 Yip GW, Ferretti P, Copp AJ. Heparan sulfate proteoglycans and spinal neurulation in the mouse embryo. Development 2002;129:2109-2119.

29 Leteux C, Chai W, Nagai K, et al. 10E4 antigen of Scrapie lesions contains an unusual nonsulfated heparan motif. J Biol Chem 2001;276:12539-12545.

30 Esteva FJ, Hortobagyi GN. Prognostic molecular markers in early breast cancer. Breast Cancer Res 2004;6: 109-118.

31 Endl E, Gerdes J. The Ki-67 protein: fascinating forms and an unknown function. Exp Cell Res 2000;257: 231-237.

32 Scholzen T, Gerdes J. The Ki-67 protein: from the known and the unknown. J Cell Physiol 2000;182:311-322.

33 Urruticoechea A, Smith IE, Dowsett M. Proliferation marker Ki-67 in early breast cancer. J Clin Oncol 2005;23:7212-7220.

34 Kocova L, Skalova A, Fakan F, et al. Phyllodes tumor of the breast: immunohistochemical study of 37 tumors using MIB1 antibody. Pathol Res Pract 1998;194: 97-104.

35 Umekita Y, Yoshida H. Immunohistochemical study of MIB1 expression in phyllodes tumor and fibroadenoma. Pathol Int 1999;49:807-810.

36 Pellegrini L. Role of heparan sulfate in fibroblast growth factor signalling: a structural view. Curr Opin Struct Biol 2001;11:629-634.

37 Lin X, Buff EM, Perrimon N, et al. Heparan sulfate proteoglycans are essential for FGF receptor signaling during Drosophila embryonic development. Development 1999;126:3715-3723.

38 Hardingham TE, Fosang AJ. Proteoglycans: many forms and many functions. FASEB J 1992;6:861-870.

39 Fernig DG, Chen HL, Rahmoune H, et al. Differential regulation of FGF-1 and -2 mitogenic activity is related to their kinetics of binding to heparan sulfate in MDAMB-231 human breast cancer cells. Biochem Biophys Res Commun 2000;267:770-776.

40 Mundhenke C, Meyer K, Drew S, et al. Heparan sulfate proteoglycans as regulators of fibroblast growth factor2 receptor binding in breast carcinomas. Am J Pathol 2002;160:185-194.
41 Nurcombe V, Smart CE, Chipperfield H, et al. The proliferative and migratory activities of breast cancer cells can be differentially regulated by heparan sulfates. J Biol Chem 2000;275:30009-30018.

42 Soussi T, Lozano G. p53 mutation heterogeneity in cancer. Biochem Biophys Res Commun 2005;331: 834-842.

43 Mohapatra S, Chu B, Zhao X, et al. Accumulation of p53 and reductions in XIAP abundance promote the apoptosis of prostate cancer cells. Cancer Res 2005;65:7717-7723.

44 Liu MC, Gelmann EP. P53 gene mutations: case study of a clinical marker for solid tumors. Semin Oncol 2002;29:246-257.

45 Tse GM, Putti TC, Kung FY, et al. Increased p53 protein expression in malignant mammary phyllodes tumors. Mod Pathol 2002;15:734-740.

46 Shpitz B, Bomstein Y, Sternberg A, et al. Immunoreactivity of p53, Ki-67, and c-erbB-2 in phyllodes tumors of the breast in correlation with clinical and morphologic features. J Surg Oncol 2002;79: 86-92.

47 Krajewski S, Thor AD, Edgerton SM, et al. Analysis of Bax and Bcl-2 expression in p53-immunopositive breast cancers. Clin Cancer Res 1997;3:199-208.

48 Krajewski S, Krajewska M, Turner BC, et al. Prognostic significance of apoptosis regulators in breast cancer. Endocr Relat Cancer 1999;6:29-40.

49 Sarlomo-Rikala M, Kovatich AJ, Barusevicius A, et al. CD117: a sensitive marker for gastrointestinal stromal tumors that is more specific than CD34. Mod Pathol 1998;11:728-734.

50 Carvalho S, Silva AO, Milanezi F, et al. c-KIT and PDGFRA in breast phyllodes tumors: overexpression without mutations? J Clin Pathol 2004;57:1075-1079.

51 Tse GM, Putti TC, Lui PC, et al. Increased c-kit (CD117) expression in malignant mammary phyllodes tumors. Mod Pathol 2004;17:827-831.

52 Kuijper A, de Vos RA, Lagendijk JH, et al. Progressive deregulation of the cell cycle with higher tumor grade in the stroma of breast phyllodes tumors. Am J Clin Pathol 2005;123:690-698. 